\title{
Membrane Distillation: A Niche Application for Wastewater
}

\author{
Ahmed Abdel-Karim* \\ Department of Water Pollution Research, National Research Centre, Egypt \\ *Corresponding author: Ahmed Abdel-Karim, Department of Water Pollution Research, National Research Centre, 33 El Buhouth St., \\ Dokki, 12622 Giza, Egypt \\ To Cite This Article: Ahmed Abdel-Karim. Membrane Distillation: A Niche Application for Wastewater. 2020 - 9(5). AJBSR.MS.ID.001426. DOI: \\ 10.34297/AJBSR.2020.09.001426.
}

Received: 誹 May 18, 2020; Published: 眥 July 22, 2020

\begin{abstract}
The sought-after efficient treatment of wastewater has become an essential purpose. in this context, Membrane Distillation (MD), which is a thermal-based membrane technology, has the ability to treat wide range of wastewater streams such as industrial wastewater, seawater, brine water from other processes, and oil-gas field produced water. MD membranes are basically hydrophobic in nature so they are susceptible to fast wetting and severe fouling. In this mini review recent efforts in using MD for treating wastewater treatment will be mentioned briefly, along with novel membranes with special anti-wetting features to overcome the trade-off between permeability and selectivity.
\end{abstract}

Keywords: Membrane distillation, Wastewater, Fouling, Wetting

\section{MD for Wastewater Treatment}

According to Choudhury et al [1], there is a growth in the number of articles published that deal with MD (about 4300 articles in 2018). More specifically, application of MD in wastewater treatment and reclamation has picked up huge attention. For instance, MD has been used for recovery of hypersaline wastewater in emerging industries (e.g., shale-gas), which cannot be dealt properly with conventional reverse osmosis membranes [1]. Besides, MD has also used as an effective technology to produce high-quality freshwater from wastewater through the utilization of waste-heat or low-grade solar or geothermal heat [2]. There are different strategies to continue the progress of energy used in MD such as improving MD system configuration, development of novel/ modified membrane material, or integration of other processes with MD [1]. Though MD is primarily adopted to be used mainly for water recovery from highly saline/brine water, MD has been tested for wastewater recovery thru use synthetic wastewater with model contaminants to assess scaling and fouling propensity [2-5].

Studies describing MD with real wastewater indicates that system performance varies significantly from studies conducted with synthetic wastewater [6,7]. Vast of published articles dealt with DCMD configuration due to simplicity and ease of operation features. In this context, textile/dyeing wastewater has been treated with Direct Contact Membrane Distillation (DCMD) [8-10]. The main findings that can be elucidated from these reports are the flux data varies significantly while retention of the pollutants is almost $100 \%$ for salts and about $99 \%$ for organics. Interestingly, no pretreatment stage is used before the recognized DCMD experiments. The main problem in oily wastewater is having low surface tension foulants so DCMD failed to efficiently remove the organic contents (TOC removal is about 50\%) with very low flux value 0.4LMH [11].

Air Gap Membrane Distillation (AGMD) configuration can overcome wetting issue in DCMD due to the existence of additional air resistance [1], was adopted to treat pharmaceutical wastewater in pilot trial [12]. AGMD also used to treat synthetic wastewater composed of salt, surfactant and dye [2], where almost all foulants have been rejected. The wetting phenomenon has been observed in 70 hours as a result of surfactant presence. besides, Vacuum Membrane Distillation (VMD) [13] of synthetic solutions prepared using dyes specifically found in textile/dyeing wastewater. VMD demonstrated complete rejection of five different dyes in a benchscale setup during short duration (less than 2 hours) experiments. 


\section{Point of View}

MD for wastewater treatment differs from saline water desalination typically due to differences in feed water composition and the interaction between contaminants and the membrane surface. It should be declared here that the fouling and wetting scenarios in MD will significantly vary in MD when used for wastewater treatment compared to desalination of saline water. It should be kept in mind that, while various pre-treatments are provided to wastewater to control fouling and wetting in MD, the justification of employing MD over RO, in recovering pre-treated wastewater, is seldom studied in detail.

A. An assortment of points must be kept in mind as interest grows for wastewater treatment using MD: the interaction between the membrane and wastewater constituents affects MD behaviour in terms of performance, membrane fouling and wetting.

B. Pre-treatment of wastewater is essential step to achieve a consistent performance of MD in wastewater treatment.

C. Lack of systematic research regarding membrane maintenance procedures.

\section{Reference}

1. Choudhury MR, Anwar N, Jassby D, Rahaman MS (2019) Fouling and wetting in the membrane distillation driven wastewater reclamation process-A review. Advances in Colloid and Interface Science 269: 370399.

2. Leaper S, Abdel Karim A, Gad Allah TA, Gorgojo P (2019) Air-gap membrane distillation as a one-step process for textile wastewater treatment. Chemical Engineering Journal 360: 1330-1340.

3. Hamzah N, Leo CP (2017) Membrane distillation of saline with phenolic compound using superhydrophobic PVDF membrane incorporated with TiO2 nanoparticles: Separation. fouling and self-cleaning evaluation, Desalination 418: 79-88.
4. Deyin Hou, Lin D, Zhao C, Wang J, Fu C (2017) Control of protein (BSA) fouling by ultrasonic irradiation during membrane distillation process. Separation and Purification Technology 175: 287-297.

5. An AK, Guo J, Lee EJ, Jeong S, Zhao Y, et al. (2017) PDMS/PVDF hybrid electrospun membrane with superhydrophobic property and drop impact dynamics for dyeing wastewater treatment using membrane distillation. Journal of Membrane Science 525: 57-67.

6. Zoungrana AZI, Elcik H, Özkaya B, Çakmakci M (2017) The treatability of landfill leachate by direct contact membrane distillation and factors influencing the efficiency of the process. Desalina Water Treat 71: 233243.

7. Zoungrana A, Zengin IH, Karadag D, Çakmakci M (2017) Treatability of Municipal Wastewater with Direct Contact Membrane Distillation. Sigma J Eng \& Nat Sci 8: 245-254.

8. Mokhtar NM, Lau WJ, Ismail AF, Kartohardjono S, Lai SO, et al. (2016) The potential of direct contact membrane distillation for industrial textile wastewater treatment using PVDF-Cloisite 15A nanocomposite membrane. Chemical Engineering Research and Design 111: 284-293.

9. Dow N, Villalobos García J, Niadoo L, Milne N, Zhang J, et al. (2017) Duke, Demonstration of membrane distillation on textile waste water: assessment of long-term performance, membrane cleaning and waste heat integration. Environmental Science: Water Research \& Technology 3: 433-449.

10. Li F, Huang J, Xia Q, Lou M, Yang B, et al. (2018) Direct contact membrane distillation for the treatment of industrial dyeing wastewater and characteristic pollutants. Separation and Purification Technology 195: 83-91.

11. Han L, Tan YZ, Netke T, Fane AG, Chew JW (2017) Understanding oily wastewater treatment via membrane distillation. Journal of Membrane Science 539: 284-294.

12. Woldemariam D, Kullab A, Fortkamp U, Magner J, Royen H, et al. (2016) Membrane distillation pilot plant trials with pharmaceutical residues and energy demand analysis. Chemical Engineering Journal 306: 471483.

13. Criscuoli A, Zhong J, Figoli A, Carnevale MC, Huang R, et al. (2008) Treatment of dye solutions by vacuum membrane distillation. Water Research 42: 5031-5037. 